\title{
Framing, metaphor and dialogue
}

\section{A multimodal approach to party conference speeches}

\author{
Camille Debras and Emilie L'Hôte \\ Université Paris Ouest Nanterre La Défense / Université Paris Diderot, \\ Sorbonne Paris Cité
}

This paper considers the Party Conference Speech as a paradigmatic example of effective political discourse, so as to identify and analyse the elements that make for the successful reception of a speech, and determine the ways in which the leader brings about consensus and generates applause. Methodologically speaking, our framework for analysis combines (i) quantitative and qualitative methods, as well as (ii) textual and multimodal analyses of the performed text. We start with a quantitative overview of party conference speeches analysed as written corpora, before zooming in on Tony Blair's 2006 party conference speech, in which we identify what non-verbal strategies come into play in the discursive construction of the leader's individual and the party's collective identities.

Keywords: Party conference speeches, discourse analysis, corpus-based methods, gesture studies, conceptual metaphor theory, framing, reception theory

\section{Introduction}

In the United Kingdom, political party conferences regularly receive substantial media and press attention, in accordance with their marked significance with respect to the parties' cohesion and evolution over the years (Faucher-King, 2005, p. 1). They can even be described as an institutional ritual (Mariot, 2006, 2009), insofar as they have an important unifying function across the three components of the party: public office, grassroots and central office (Mair, 1994). ${ }^{1}$ Within this

1. Yet they remain under-investigated in the area of political discourse analysis (Finlayson \& Martin, 2008, p. 455). Studies like Faucher-King (2005) or Heritage \& Greatbatch (1986) have focused on their significance from the standpoints of anthropology and political sociology, or of conversation analysis. See also Minkin (1978), and more recently Pettitt (2012) and Bull (2012). 
specific political setting, the leader's speech at the Conference functions as "the rallying finale of [the] conference" (Faucher-King, 2005, pp. 80-82). As such, it is more often than not termed the 'most important speech' of a politician's career. In Labour's history, these speeches have set the scene for crucial moments in the life of the party, such as Kinnock's 1985 attack on Militant, or Blair's launch of the new Clause IV. Still formally referred to as "the Parliamentary Report" in the conference programme, it originally consisted of a written document destined to be critically examined by delegates, which led to much debate (Minkin, 1978, p. 214). Things changed after the Second World War: Attlee decided to use the report to address the conference directly, and this practice was resumed by Wilson in the 1960s. The shift gradually affected the very nature of the speech, which stopped being the subject of critical discussion, and was rather "made under circumstances which guarantee its uncritical reception" (Minkin, 1978, p. 216). Debate was replaced by "prolonged applause", as the speech became the "symbol of leadership pre-eminence" (1978, p. 216), thereby bringing it closer to its Conservative counterpart. On both sides of the political spectrum, the leader's speech at the party conference now takes the form of a political ritual where consensus prevails: the leader bonds with the members of the party as the speech reasserts the party's collective identity, and the party leader is preaching to the choir.

This is why in this paper, we propose to consider the Party Conference Speech as a paradigmatic example of effective political speech, so as to identify and analyse the elements that make for the successful reception of a political speech, and determine the ways in which the leader brings about consensus and generates applause (Heritage \& Greatbatch, 1986). We aim to account for the successful impact of a political speech on its audience. We argue that multiple points of entry are needed to get a full picture of such a complex research object. Therefore our framework for analysis combines quantitative and qualitative methods at the textual level, with a multimodal analysis integrating speech, prosody and gesture. We start with a quantitative overview of party conference speeches analysed as written corpora, before zooming in on Tony Blair's 2006 speech, so as to identify what non-verbal strategies come into play in the discursive construction of the leader's individual, and the party's collective, identities.

\section{Corpus and methods}

\subsection{Corpus description}

A corpus of political speeches was compiled to bring out the specific features of the leader's speeches at the party conference. It comprises 4 sub-corpora, which are 
described in this section. The first sub-corpus is a compilation of the Labour leader's speeches at party conferences (henceforth LPCS, for 'Labour Party Conference Speeches') from 1994 to 2013. LPCS contains 119, 805 words, and includes 20 speeches. The second Labour sub-corpus is a compilation of non-party conference speeches delivered by the leader of the party for the same time period (henceforth LnPCS, for 'Labour non-Party Conference Speeches'). LnPCS contains 144,786 words and includes 46 speeches. A parallel set of sub-corpora was compiled for the Conservative Party. The sub-corpus consisting of the Conservative leader's speeches at party conferences (henceforth TPCS, for 'Tory Party Conference Speeches') contains 107,245 words, and includes 20 speeches. Similarly, the second Conservative sub-corpus is a compilation of non-party conference speeches delivered by the leader of the party for the same time period (henceforth TnPCS, for 'Tory non-Party Conference Speeches'). TnPCS comprises 85,791 words and 28 speeches.

This paper aims at drawing comparisons that go beyond traditional divisions on the British political spectrum, and look at the leader's party conference speech as a prototypical example of effective political discourse, regardless of political allegiance. For this purpose, all party conference speeches were compiled into the corpus section called PCS, containing 227,052 words and including all 40 speeches mentioned above. Its non-party conference counterpart (henceforth nPCS) contains 230,581 words and includes 74 speeches. Comparisons between PCS and $\mathrm{nPCS}^{2}$ will not obscure differences between parties, and do not presume that Labour and Conservative discourse are one and the same object of study; instead they focus on party conference speeches as prototypes of political discourse in the first instance, which means that party-specific distinctions are identified as relevant, but come second in our analyses.

The overall size of this preliminary collection of texts is 457,633 words; the overall corpus is composed of 114 speeches. This allows us to obtain valid statistical results and identify statistically significant discourse patterns, which we focus on in the qualitative part of our analysis.

Party conference speeches are not just textual transcripts that can be analysed for verbal content. They are also spoken performances, delivered in front of an audience of party members, which are accessible through video recordings. Thus our analyses focus on both text and non-verbal elements like prosody, gesture, posture and facial expression. Such speeches also have a fundamentally dialogical dimension. The speaker addresses an audience that reacts during the course of the speech, albeit with the limited repertoire of laughter and applause. Some

2. Acronyms like PCS are used in the paper to refer to both the relevant (sub-)corpus, and to individual examples of items in the corpus. 
of the multimodal resources mobilized in the spoken performance are devoted to anticipate, trigger (see Heritage \& Greatbatch, 1986) or respond to the audience's reactions in this asymmetrical dialogue. In the qualitative section of the paper, we analyse the text and video recording of Blair's 2006 party conference speech, as one representative example of effective political discourse. It is 56 minutes and 23 seconds long, and contains 5227 words. ${ }^{3}$ Before focusing on one of Blair's PCS in the qualitative multimodal part of our study, we deal more specifically with elements that are characteristic of new ${ }^{4}$ Labour discourse.

\subsection{Theoretical background}

Frame semantics (Fillmore, 1982; Lakoff, 2002, 2006) and Conceptual Metaphor Theory are at the basis of the work carried in our analysis of political discourse. As established by Lakoff (1993, p. 194), the primary purpose of conceptual metaphor is to create understanding. Metaphor also determines understanding because it only allows for partial profiling of concepts (Kövecses, 2002, p. 81). This element of human cognition is particularly relevant to political discourse. Politicians use conventional aspects of conceptual metaphors to frame or reframe parts of their agendas, and knowing what elements are profiled in a particular metaphor also raises awareness of the elements that are hidden (Semino, 2008). What is not profiled in political discourse is often as important as what is brought to the foreground, and the discourse of the two main British political parties is no exception to this rule. Previous studies of metaphor in political discourse have focused on specific target domains to see how selected issues are framed in discourse (e.g., globalization in L'Hôte $(2010,2014)$ ) and on how specific source domains participate in political discourse strategies (e.g., religion in Charteris-Black (2004)). These studies rely on Fillmore's initial (1982) definition of 'semantic frames', as words and constructions that invoke a known scenario for a situation or an event, and on what Lakoff (2006) has termed 'surface frames', i.e. mental structures associated with specific lexical elements.

In this paper however, our main goal is to propose a study of party conference speeches as a paradigm of effectiveness in political discourse, by highlighting their main characteristics. We argue that such speeches in the UK aim at touching the audience's emotions and values, at generating consensus and at celebrating the party as a united entity. Therefore, this study focuses more on the 'deep frames' at stake in discourse and gesture, i.e. basic frames that constitute people's

3. See http://www.youtube.com/watch?v=1PCYPPKp7ts for the video version of Blair's 2006 PCS (accessed 07/07/14).

4. The adjective new in the name of the party was never officially capitalized (L'Hôte, 2014). 
worldviews, define what is understood as common sense, and are connected to values and principles (Lakoff, 2006). In particular, it relies on Lakoff's conceptual models of politics of the Strict Father and the Nurturant Parent (2002). These models are built on a series of conceptual metaphors bringing together nation and family (Lakoff, 2002, p. 153), namely THE NATION IS A FAMILY, THE GOVERNMENT IS A PARENT and THE CITIZENS ARE THE CHILDREN. The Strict Father model is defined by a dominant father figure whose priorities include moral strength and obedience to authority figures (Lakoff, 2002, p. 35). While Lakoff's analysis contains a lengthy list of metaphors included in the Strict-Father model, Cienki (2005a, p. 281) highlights MORALITY IS STRENGTH, BEING GOOD IS BEING UPRIGHT and MORALITY IS PURITY as having the highest priority. At the other end of the spectrum, the Nurturant-Parent model is defined by a more horizontal and nongendered parental structure, whose main values include caring, empathy and nurturance (Lakoff, 2002, p. 35). Cienki (2005a, p. 281) highlights the following moral metaphors as central to the model: MORALITY IS EMPATHY, MORAL ACTION IS NURTURANCE and MORAL GrowTH Is PHYSICAL GROWTH. Deep frames such as these models, along with large schemas such as those L'Hôte (2014) has identified as new Labour's narrative of change and progress, contribute to the selection of many surface frames - metaphorical or not - in discourse and gesture, but they may not always be identified by a precise series of source-to-target mappings expressed in the text. Cienki's (2005a) empirical testing of Lakoff's theoretical models suggests that reasoning in terms of conceptual models may occur more "through non-metaphorical language than through verbal metaphoric expressions" (Cienki, 2005a, p. 304). His analyses also lend support to the definition of a conceptual model as "something which a cultural group ('supra-individual') has a mastery of, rather than any one individual speaker. Only some of the metaphors which cohere as part of a cognitive/cultural model may belong to an individual's repertoire" (p.305).

Cienki's empirical study highlights the relevance of our reliance on gesture analysis. He remarks that some of the metaphors identified by Lakoff in connection with the Strict-Father and the Nurturant-Parent models may be expressed more frequently in the gestures of speakers than in their discourse. We elaborate on this idea in Section 4.

\subsection{A corpus-based multimodal analysis of political discourse}

In this study, we present a corpus-based multimodal analysis of political discourse. Our approach is a variation on the "methodological synergy" advocated by Baker et al. (2008, p. 274) in their analysis of the discourse of refugees and asylum seekers in the British press. It is based on the assumption that "'qualitative' findings can 
be quantified, and that 'quantitative' findings need to be interpreted in the light of existing theories, and lead to their adaptation, or the formulation of new ones" (p. 296). Our approach differs from Baker et al's in the detail of the methodological steps proposed (p.295), as it incorporates cognitive linguistics and multimodality. The analysis proceeds along six steps, which are detailed below.

i. The analysis starts with the formulation of research hypotheses informed by a context-based analysis of our main topic - the specificities of the leader's party conference speeches as a model of effective political discourse.

ii. The full lists of significant keywords and key concepts for each of our corpus comparisons are the starting point of our analyses. Significant differences between the corpora are studied in detail so as to determine larger patterns.

iii. Significant keywords and key concepts are manually selected from the list for each of the larger issues at stake in the study.

iv. Concordance analyses for given elements in the lists yield necessary contextual information on the words/concepts under scrutiny. Collocation analyses are also taken into account, especially in the case of high-frequency words.

v. Our initial research questions and hypotheses are then detailed further.

vi. Based on these refined hypotheses, we proceed to the second part of the process, which is a qualitative focus on a sample speech from our corpus data. The detailed study of the full text and the video version of Blair's 2006 party conference speech allows us to analyse these claims further: we focus on elements that, while more difficult to quantify, are essential to our study, namely metaphor ${ }^{5}$ and deep frames, as well as gesture and other multimodal factors at play.

5. We relied on the method developed by the Pragglejaz Group (2007) for the identification of lexical units used metaphorically in the text of the speech. A contemporary audience was assumed for the analysis. Phrasal verbs were treated as one single lexical unit. WMatrix's multiword units were not retained as a measure of lexical units for the analysis, in accordance with the Pragglejaz group's original decision regarding frequent collocations (Pragglejaz Group, 2007). Word-class boundaries were not crossed (Steen et al., 2010). The "New Oxford American Dictionary" was used as a reference. C. Debras and E. L'Hôte were the two analysts in charge of coding of the data. Discussion between coders took place after each finished their first 'pass'. When a mention of the target domain for the metaphor was available in the immediate co-text - in the same sentence, or in the sentence immediately preceding or following the analysed word, the conceptual metaphor was identified based on this textual occurrence. When the target domain was not explicitly mentioned, identification of the conceptual metaphor was determined after a discussion between the two analysts. Statistical analysis on inter-analyst agreement is planned in the next steps of the project. Non-metaphorical entailments of Lakoff's metaphorical models of politics could not, however, be identified with the same procedure. 
The rest of this section details some of the key elements to our approach, namely our reliance on WMatrix for the quantitative part of our study and the grid designed for gesture analysis of Blair's speech.

\subsubsection{WMatrix and statistics}

WMatrix is an online tool for corpus analysis and corpus comparison that produces concordance tables, frequency lists, collocation tables and keyness analyses (see definition below) (Rayson, 2003, 2009). ${ }^{6}$ The dataset is tagged for parts of speech (PoS) using CLAWS ${ }^{7}$ (Rayson, 2003, p. 64). ${ }^{8}$ Semantic annotation for semantic concepts is performed using USAS. ${ }^{9}$

WMatrix's keyness analysis is a comparison between two frequency lists using $\log$ likelihood ratio as a statistical test (Meyer, 2002, p. 126). One of WMatrix's strong points is that keyword analysis is then extended to analyses of key PoS and key semantic concepts. Each word/semantic tag/PoS tag in the primary corpus is compared with its equivalent in a secondary corpus; the software then evaluates whether the difference between the frequencies in the two corpora is statistically significant or not ${ }^{10}$ and finally reorders the word/tag list according to the statistical score obtained. WMatrix identifies both positive keywords - words that are over-represented in the primary corpus, and negative keywords - words that are under-represented in the primary corpus. ' + ' signs are displayed next to positive keywords in the table, and '-' signs indicate negative keywords.

\subsubsection{Multimodal analysis}

The video was annotated in ELAN ${ }^{11}$ for the multiple non-verbal dimensions of the speaker's performance, including the forms and functions of hand gestures, head

6. For detailed descriptions and a discussions of concordance tables, concordance analysis and collocations, see Sinclair (1991), Baker (2006, pp.92-93), and Archer (2009). For a detailed discussion of frequency lists, see Rayson (2008).

7. Constituent Likelihood Automatic Word-tagging System.

8. See Rayson (2003, p. 66) for a detailed description of the entire tagset.

9. UCREL Semantic Analysis System.

10. It is hard to find any kind of popular consensus about cut-off points in the literature (Baker, 2004 , p. 351). Because of the generally skewed nature of corpus data (Oakes, 1998, p. 4) and the fact that multiple comparisons are often carried out on the same data set, we have chosen to move from a standard cut-off point at $\mathrm{p}=0.01$ to results yielding a $\mathrm{p}$-value inferior to 0.0001 , which means an LL score equal to or greater than 15.13.

11. ELAN is a free video annotation software available from: http://www.lat-mpi.eu/tools/elan/ download 
movements and facial variations like raised eyebrows. As the literature on gesture has shown, there is no absolute categorization for gesture functions, and several gesture typologies have been established, including those by McNeill (2005, pp. 38-41), Müller (1998) and Kendon (2004, pp. 158-159). We have therefore created a specific template for the annotation of a speech performed in the presence of an audience, composed of the following tiers: ${ }^{12}$

i. Head movements: single nod, head nod, head shake, head tilt (to the side), other;

ii. Facial expressions: raised eyebrows, tense mouth, other;

iii. Hand gesture forms: precision grip, index pointing up, both palms straight facing each other, open palm(s) lateral, other;

iv. Hand gesture functions: referential, abstract referential (metaphoric), deictic, pragmatic, prosodic beat;

So as to characterize the speech's impact on the audience, another tier (v) was added to annotate the audience's reaction to the speech: laughter, applause, other.

Using online material for multimodal analysis has advantages and drawbacks. When the video is available online, it can easily be downloaded right away in a convenient format. Yet a major issue arises with most political speeches that are already edited for media broadcasting. Most of the time, the camera zooms in to get a medium close-up of the politician, leaving out a large part of the speaker's gesture space. The multiple cameras used to record the speech also regularly focus on the audience members' reactions, especially on people mentioned in the speech who are part of the audience, or on general audience reactions such as applause or laughter. Such angles can be included in the final editing of the video recording, at times when the political leader may be speaking and gesturing. As a consequence, prosody remains accessible continuously but gestures are not always fully visible, because the camera's focus is either too close or away from the speaker. And yet, the video's editing usually does not hinder gesture analysis: facial expressions and head movements are accessible when the camera is on the speaker, while most of his hand gestures are ample and salient enough to be seen by the whole audience, thus remaining within the camera's angle.

12. In ELAN, a template is a structure of annotation lines called 'tiers'. The annotator can freely adapt the annotation scheme to his or her research project; for instance, annotation tiers can be independent or organised in a hierarchy. 


\section{Quantitative analysis: Connecting with the audience}

In the quantitative part of our study, we identified three key dimensions of PCS through which the speaker builds a strong and direct connexion with his various audiences (at the conference, on TV, online). To win them over, the speaker emphasizes the interpersonal dimension of his address by framing it as an intimate relation even with a distant, indirect audience (TV, Internet). He favours affect and values over political reasoning, by presenting political stakes in a non-technical way. He brings consensual elements to the fore to seal the party's collective identity.

\subsection{Intimacy at a distance}

Based on our keyness analyses, we identified various ways in which PCS stage the words of the leader in connection with the symbolic function of institutional events. (i) PCS call attention to their circumstances of production; (ii) PCS present the leader as addressing his people; (iii) PCS are delivered more like an informal exchange with the audience than a highly formal speech.

First of all, (i), the leader's Party Conference Speeches call attention to their circumstances of production, as shown in Table 1.

Table 1. Staging the speech: keyword list 1

\begin{tabular}{lllllll}
\hline Word & PCS (n) & PCS (\%) & nPCS (n) & nPCS (\%) & + /- & LL PCS-nPCS \\
\hline debate & 33 & 0.01 & 121 & 0.05 & - & 52.11 \\
problems & 62 & 0.03 & 137 & 0.06 & - & 27.83 \\
Mr._President & 26 & 0.01 & 0 & 0 & + & 36.45 \\
conference & 84 & 0.04 & 36 & 0.02 & + & 20.5 \\
week & 90 & 0.04 & 41 & 0.02 & + & 19.55 \\
next_year & 47 & 0.02 & 16 & 0.01 & + & 16.42 \\
bill & 6 & 0 & 32 & 0.01 & - & 19.13 \\
parliamentary & 4 & 0 & 26 & 0.01 & - & 17.69 \\
constitutional & 11 & 0 & 38 & 0.02 & - & 15.33 \\
\hline
\end{tabular}

The noun conference itself is significantly more frequent in PCS than in nPCS $(\mathrm{LL}=20.5, \mathrm{p}<0.0001)$. Additionally, party conferences on both sides of the aisle last for a week $(\mathrm{LL}=19.55, \mathrm{p}<0.0001)$, they look forward to the year ahead (next_ year ${ }^{13}: \mathrm{LL}=16.42, \mathrm{p}<0.0001$ ), and involve frequent mentions of the President $(\mathrm{LL}=36.45, \mathrm{p}<0.0001)$. Party conferences can be understood as a specific kind of political ritual, which aims at creating unity between the different branches of the

13. In WMatrix, some phrases are identified as 'multi-word-expressions', or single semantic units, and thus automatically joined by underscore characters e.g., red_tape, or tuition_fees. 
party - especially in the case of the Labour Party, as detailed in the introduction. The fact that words like bill, parliamentary and constitutional are in significant underuse in PCS compared with nPCS calls attention to these specific circumstances. The nouns debate and problems occur significantly less in PCS than in NPCS, thereby confirming the role of the leader's speech as seeking consensus. Additionally, report is not identified as a keyword in any of our corpus comparisons, which confirms Pettitt's claim (2012) that the reference to the leader's speech as "the Parliamentary Report" in the Conference programme is no more than lip service.

The leader's speeches to the party conference also emphasize the privileged connection between the speaker and his supporters (ii). As shown in Table 2, references to $I$ and $y o u$ and their related determiners and pronouns are significantly more frequent in PCS than in NPCS.

Table 2. Staging the speech: keyword list 2

\begin{tabular}{lclclll}
\hline Word & PCS $(\mathbf{n})$ & PCS $(\%)$ & nPCS $(\mathbf{n})$ & nPCS $(\%)$ & $+/-$ & LL PCS-nPCS \\
\hline i & 2850 & 1.26 & 1611 & 0.7 & + & 368.06 \\
you & 1671 & 0.74 & 824 & 0.36 & + & 306.54 \\
my & 464 & 0.2 & 270 & 0.12 & + & 54.93 \\
people & 1700 & 0.75 & 1382 & 0.6 & + & 37.96 \\
your & 364 & 0.16 & 237 & 0.1 & + & 29.03 \\
mine & 24 & 0.01 & 4 & 0 & + & 16.16 \\
\hline
\end{tabular}

In example (1) below, the connection between the speaker and the audience is made very clear through the repetition of the phrase I want you, as well as the reliance on the lexicon of inclusion, with words like together or head and heart.

(1) The people of this country are not looking to $u$ s for a revolution. They want us to make a start. I want you with me in that task. I want you with me. Head and heart. Because this can only be done together. Leaders lead, but in the end the people govern (LPCS). ${ }^{14}$

There is a distinction between the people of this country and you, which points to the audience. So the two mentions of us in the example can refer to the leaders and thereby metonymically to the party as an entity, as well as to the combination of leader and supporters that is established semantically and syntactically in the speech. Based on this evidence, we suggest - unlike Pettitt (2012) - that selfreference in party conference speeches is a means of establishing a clear connexion with the audience (see also Benveniste (1966)), and of focusing on interpersonal relations in the speech, so as to create a valuable impression of 'intimacy at a

14. In this example as in all the following ones, the italics are ours. They highlight key elements in each of the quotes. 
distance' (Horton \& Wohl, 1956). As Horton \& Wohl remark, one striking feature of mass media communication is for the speaker to adopt a conversational style usually reserved to face-to-face conversation when addressing an audience that is in fact not present, but at the other end of the TV, or behind their computer watching the speech on YouTube. In the specific case of PCS, the addressed audience is a hybrid of present and absent public: an audience is present where and when the speech is delivered, but the speech is also designed and filmed to be broadcast on $\mathrm{TV}$ and on the Internet. In that respect, strategies meant to create intimacy at a distance also serve to win over the immediate audience of the conference.

In the same vein, Table 3 points to an increased presence of discourse verbs in the leader's party conference speech.

Table 3. Staging the speech: keyword list 3

\begin{tabular}{lclclll}
\hline Word & PCS $(\mathbf{n})$ & PCS $(\%)$ & nPCS $(\mathbf{n})$ & nPCS $(\%)$ & $+/-$ & LL PCS-nPCS \\
\hline tell & 234 & 0.1 & 71 & 0.03 & + & 94.35 \\
know & 495 & 0.22 & 247 & 0.11 & + & 88.38 \\
yes & 191 & 0.08 & 60 & 0.03 & + & 73.91 \\
you_know & 66 & 0.03 & 9 & 0 & + & 49.82 \\
said & 292 & 0.13 & 162 & 0.07 & + & 39.78 \\
told & 109 & 0.05 & 37 & 0.02 & + & 38.23 \\
no & 515 & 0.23 & 351 & 0.15 & + & 33.83 \\
say & 412 & 0.18 & 274 & 0.12 & + & 30.12 \\
think & 266 & 0.12 & 166 & 0.07 & + & 24.93 \\
i_believe & 99 & 0.04 & 44 & 0.02 & + & 22.57 \\
look & 47 & 0.02 & 13 & 0.01 & + & 20.99 \\
argued & 2 & 0 & 23 & 0.01 & - & 20.4 \\
claim & 9 & 0 & 36 & 0.02 & - & 16.93 \\
hear & 54 & 0.02 & 20 & 0.01 & + & 16.75 \\
i_say & 71 & 0.03 & 31 & 0.01 & + & 16.74 \\
\hline
\end{tabular}

These verbs are connected to rhetorical strategies that allow the speaker to present himself as having a conversation with the audience (iii), and with the people of Britain at large as in example (2), or to summon the presence of interlocutors voicing dissent, in order to pre-empt criticism and generate agreement around him, as in examples (3) and (4).

(2) I spoke to a woman the other day, a part-time worker, complaining about the amount of her tax credit. I said: hold on a minute: before 1997, there were no tax credits not for working families not for any families; [...] And no minimum wage, no full time rights for part time workers, in fact nothing. So what?, she said that's why we elected you. Now go and sort out my tax credit. And, of course, she's right (LPCS). 
(3) Now, I hear people, some of them in our own party, falling for the Tory attack that we have no policies. What nonsense (LPCS).

(4) Did you hear what Ed Miliband said last week about taxes? He described a tax cut as the government writing people a cheque. Ed... Let me explain to you how it works. When people earn money, it's their money (TPCS).

In example (2), the anecdote stages a conversation between a woman and Tony Blair, which allows him to present his argument about new Labour's social achievements in a more concrete light. The conclusion of the story (Now go and sort out my tax credit) gives a humorous tone to an otherwise dry economic account, and allows the speaker to praise his own achievement while still presenting the people in the audience as wiser than himself. In example (3), the indefiniteness of the speaker's interlocutor serves less as the staging of a humorous cautionary tale than as a way to dismiss all attempts at dissent - within and outside the party - as irrelevant. As criticism is voiced by the speaker only, it is necessarily him who has the last word (What nonsense). In example (4), a similar technique is at work, but the interlocutor is clearly identified as Ed Miliband. The passage starts with an actual quote by the Labour leader, and continues with a fictional conversation in which the speaker - David Cameron - gives him a lesson in finance (Let me explain to you how it works). In both cases, dissenting opinions are staged, but immediately rejected in favour of consensus over the leader's words. This is confirmed by the significant underuse of the only two discourse verbs with more negative prosody (see Sinclair, 1991) than the others listed in Table 3, namely argued and claim. The aim of the speaker is to stage dialogue, not debate.

Finally, Table 4 signals that marks of orality are significantly more frequent in PCS than in nPCS.

Table 4. Staging the speech: keyword list 4

\begin{tabular}{lclclll}
\hline Word & PCS (n) & PCS (\%) & nPCS (n) & nPCS (\%) & + /- & LL PCS-nPCS \\
\hline n't & 1213 & 0.53 & 533 & 0.23 & + & 282.56 \\
's & 1951 & 0.86 & 1074 & 0.47 & + & 271.65 \\
've & 436 & 0.19 & 120 & 0.05 & + & 195.69 \\
're & 436 & 0.19 & 160 & 0.07 & + & 137.12 \\
'll & 143 & 0.06 & 26 & 0.01 & + & 90.99 \\
'm & 157 & 0.07 & 45 & 0.02 & + & 67.49 \\
'd & 109 & 0.05 & 23 & 0.01 & + & 62.21 \\
thing & 172 & 0.08 & 98 & 0.04 & + & 21.7 \\
well & 139 & 0.06 & 78 & 0.03 & + & 18.33 \\
for_example & 1 & 0 & 73 & 0.03 & - & 90.89 \\
indeed & 9 & 0 & 82 & 0.04 & - & 66.31 \\
\hline
\end{tabular}


While the presence of these marks may be a question of transcription conventions, they either point to a conscious emphasis on the spoken nature of the speech, or to its reception as a performance with a heightened spoken character compared with other, more formal speeches. Additionally, the high frequency of the noun thing or the adverb well confirm the spoken character of the speech, as in examples (5) and (6).

(5) [W]e are doing the right thing, and we are on the right track for Britain (LPCS).

(6) Our task is to promote the real things, and expose the counterfeit (TPCS).

The noun thing is used very frequently both in written and spoken English, and occurs in a variety of colloquial set phrases such as the only thing, the one thing, the real thing or the thing is (Barlow, 2000). On the other hand, words that signal reasoning based on more complex logical relations (indeed, for example) are identified as being in significant underuse in PCS compared to nPCS. This is confirmed by the semantic concept A2.2 (Cause \& Effect / Connection), which is also identified as a negative key concept in a PCS-nPCS comparison ( $L L=23.91$, $\mathrm{p}<1 \mathrm{e}-4)$.

All in all, a first striking feature of party conference speeches is a meta-discursive representation of the speech itself as a dialogical event. The speaker insists on the here-and-now of the speech, highlighting his relation with the discourse's immediate addressees: the audience attending the conference. The speech relies on various strategies to tighten the bond between the leader and the party. It is a bond that is interpersonal in nature, based on an explicit relationship between 'I' and 'you'. Marks of orality bring the speech closer to an informal exchange, creating closeness with the audience. The dialogical aspect is also highlighted by discourse verbs: the speaker stages the speech by emphasizing its discursive nature and resorting to stories and anecdotes. Finally, debate and dissent are rejected: the speaker must be agreed with, regardless of potential objections.

\subsection{Affect over policy}

The second pattern identified by our quantitative analyses is that Party Conference Speeches, as most political speeches, talk about politics - but they do so by giving prominence to affect over argument and policies. These findings are consistent with Lakoff's claim that people vote for their values more than they vote for policies and arguments (Lakoff, 2002), as shown in Table 5. 
Table 5. Talking politics: keyword list 1

\begin{tabular}{lclclll}
\hline Word & PCS (n) & PCS (\%) & nPCS (n) & nPCS (\%) & + /- & LL PCS-nPCS \\
\hline NHS & 259 & 0.11 & 86 & 0.04 & + & 93.5 \\
taxes & 136 & 0.06 & 37 & 0.02 & + & 61.78 \\
EU & 21 & 0.01 & 101 & 0.04 & - & 55.84 \\
universities & 23 & 0.01 & 91 & 0.04 & - & 42.35 \\
european_union & 18 & 0.01 & 76 & 0.03 & - & 37.61 \\
social_security & 5 & 0 & 46 & 0.02 & - & 37.35 \\
economic & 128 & 0.06 & 246 & 0.11 & - & 36.08 \\
cuts & 58 & 0.03 & 11 & 0 & + & 35.84 \\
cancer & 40 & 0.02 & 4 & 0 & + & 34.75 \\
pensioners & 61 & 0.03 & 13 & 0.01 & + & 34.54 \\
WMD & 2 & 0 & 31 & 0.01 & - & 30.21 \\
job & 165 & 0.07 & 95 & 0.04 & + & 20.18 \\
\hline
\end{tabular}

Overall, in PCS, policies that are perceived as too far removed from the voters, too complex or too controversial are mentioned significantly less than in nPCS. This is notably the case for universities, the EU, or WMD. Policies that are mentioned significantly more frequently in PCS are first of all the ones that can touch voters to their core, as illustrated by the words cancer and job for instance. Some results in Table 5 may appear paradoxical at first glance: economic is in significant underuse in PCS, while taxes and cuts are positive keywords. Similarly, while social_security occurs significantly less often in PCS than in nPCS, we get opposite results for NHS. These apparent contradictions actually confirm earlier claims: they suggest that PCS tends to favour frames that are symbolically charged with the public, as opposed to nPCS that rely more frequently on more technical, specific terms to talk about similar policies. The goal of the speaker is to appeal to emotion rather than reason and to rely on the audience's attachment to political symbols, rather than proceed with a complex political argument based on facts. Such focus on affect highlights the role of PCS as institutional rituals (Mariot, 2009), whose first and foremost function is to unite the party around its leader in a moment of shared emotion (Mariot, 2006, p. 98).

\subsection{Generating consensus}

Finally, Party Conference Speeches re-emphasize the party's collective identity. The speeches focus on elements of the party's identity about which everyone agrees or on which the speaker wants everyone to agree, as shown in Table 6. 
Table 6. The party's collective identity: keyword list 1

\begin{tabular}{lclllll}
\hline Word & PCS $(\mathbf{n})$ & PCS $(\%)$ & nPCS (n) & nPCS (\%) & $+/-$ & LL PCS-nPCS \\
\hline generation & 150 & 0.07 & 61 & 0.03 & + & 40.13 \\
tough & 140 & 0.06 & 56 & 0.02 & + & 38.5 \\
family & 206 & 0.09 & 109 & 0.05 & + & 31.88 \\
love & 64 & 0.03 & 16 & 0.01 & + & 31.58 \\
common_sense & 65 & 0.03 & 18 & 0.01 & + & 28.99 \\
choice & 174 & 0.08 & 91 & 0.04 & + & 27.73 \\
journey & 36 & 0.02 & 7 & 0 & + & 21.85 \\
wrong & 156 & 0.07 & 94 & 0.04 & + & 16.51 \\
\hline
\end{tabular}

The keywords listed in the latter point to key elements in each of the parties' identities ${ }^{15}$ which are in significant overuse in PCS compared to nPCS. Some words are specific to a given speech in the data, and thus represent a specific moment in the lives of the parties. For instance, the multi-word expression common sense is not evenly distributed in our data. It appears mainly in David Cameron's 2010 PCS, in which he defines the Conservatives' Common Sense Revolution, as illustrated in example (7):

(7) Only by trusting the instincts and the individuals and the institutions and the independence of the people of this country can we hope to seize the opportunity that this Government is so tragically squandering. That's why we're going to lead a Common Sense Revolution. That's why we're going to govern for the hard-working, hard pressed, decent law abiding people of this country and bring an end to the rule of the small out-of-touch new Labour clique that thinks it is so much better than the rest of us (TPCS).

Inclusive phrases such as the people of this country, or the rest of us are repeated in connection with Cameron's motto. It is meant to present the Conservatives as closer to the population and oppose them to a new Labour clique supposedly disconnected from the needs of the people. This is part of a general strategy to create a more compassionate branding for the party (Bale, 2010), which requires the speaker to frame the Labour party as a group of heartless bureaucrats. The recurrent reference to common sense in Cameron's speeches may actually kill two birds with one stone and speak to the more traditional branch of his supporters: it can be taken as a reference to Margaret Thatcher's Speech at the 1980 party conference, in which she hopes for "a winter of common sense" - the Conservative alternative to the 1978-9 "winter of discontent" which Labour Prime Minister Callaghan had to face right before losing the 1979 General Election. A similar argument can be

15. For a detailed analysis of party identity in the Blair era, see among others L'Hôte (2010, 2014) and L'Hôte \& Lemmens (2009). 
made for the noun generation, which points to Ed Miliband's new rallying call of Labour's "new generation" in his 2010 and 2011 PCS.

Other words in Table 6 are more evenly distributed in the data, reflecting more stable elements in the framing of the parties' identities. The prominence of the noun choice is far from surprising: the prototypical concept of choice plays an essential role in Conservative philosophy, and has been taken over and transformed into what L'Hôte (2010) has termed "no-alternative choice" in new Labour discourse. As for the noun journey, it is mostly used metaphorically in new Labour discourse. It is part of the party's narrative of change and modernisation, which played a major role in the discourse of the party from Blair's start as leader in 1994 to the 2010 elections (see L'Hôte (2014) and L'Hôte \& Lemmens (2009) for more detail on the issue). Words like tough, love, family and wrong point to a radical change in the framing of Labour's identity during the Blair era, i.e. the partial adoption of the deep frames associated with a Strict-Father model of politics (Lakoff, 2002). As discussed in L'Hôte (2014), this complex deep frame was first used in connection to the issues of crime and defence before pervading the entire discourse of the party, in order to defuse Labour's soft stereotype in the minds of the public.

Quantitative analyses have allowed us to identify three relevant patterns in our corpus data. Party conference speeches stage the words of the speaker in a manner that calls attention to the ritualistic conditions of their production, while emphasizing the importance of a strong interpersonal connexion between the leader and the audience, and the leader and the country. When dissent is given a voice through the words of the leader, it is immediately contradicted and rejected as invalid, thereby forcing consensus under the appearance of true dialogue. Party conference speeches also use specific frames to talk about politics: far from being a detailed policy exposé, the speech aims at touching the audience's emotions and values. In contemporary Britain, the role of party conference speeches is to generate consensus and to celebrate the party as a united entity. Based on these first findings, we hypothesize that key metaphors and frames also consistently organize the verbal and non-verbal dimensions of the PCS when it is envisaged as a spoken performance, for optimum effectiveness of discourse. In order to elaborate on this new hypothesis, we provide a multimodal analysis of Tony Blair's 2006 party conference speech in the following section.

\section{A multimodal analysis of Blair's 2006 PCS}

In 2006, Blair gave his last conference speech as leader, as he resigned from his position as Labour leader and as Prime Minister one year later, leaving Gordon 
Brown in charge. Blair explicitly presents this Conference Speech as his last one. This speech performance is no exception to the phenomena observed in the previous section of this paper: it emphasizes the interpersonal relation between the speaker and his audience and asserts the party's defining values so as to foster consensus around its collective identity. The most salient features of Blair's 2006 PCS correspond to three deep frames that are specific to contemporary Labour discourse. First, Blair's 'tough' rhetoric is typical of Labour's shift towards the Strict Father model (Lakoff, 2002) under his leadership. Second, the idea of forward movement and its connected metaphors are anchored in Labour's consensual narrative of progress and change. Third, the assertion of the party's collective identity as the people's party is highlighted by a multimodal discourse of inclusion. In this section, we analyse deep frames from a multimodal perspective, showing how they are instantiated not only in speech, but also in the gestures used by the speaker. Gestures can serve multiple functions with respect to the verbal discourse (Kendon, 2004), for instance by representing, structuring, or even countering it. This means that the fundamental deep frames and schemas at play in the speech can be expressed in the verbal content and the gestures simultaneously, or in only one of these two modalities at a given time. For instance, even when Blair's words do not refer to the Strict Father model, this deep frame can still be expressed in the speaker's gestures, thereby strengthening the consistency of the discourse. The simultaneous and sequential combination of verbal content and gesture contributes to a successful reception on the part of the various audiences addressed by Blair.

\subsection{Tough rhetoric}

As shown in Table 6 above, the word tough is significantly more frequent in PCS, which points to a recent shift in new Labour discourse. Being 'tough' was first applied to the issue of crime, before gradually pervading all topics of political and social life in Labour discourse, in connection with a partial adoption of the StrictFather model of politics on the part of the Labour leader. As stated by Cienki (2005a) in his analysis of Lakoff's models of the Strict Father and the Nurturant Parent in US Presidential Debates, these models point to deep frames that structure political discourse and our understanding of politics, but they occur rather rarely as textual realisations of the metaphors. Our multimodal analysis of Blair's 2006 PCS expands on these findings. We identify textual entailments of the models, as in (8):

(8) I always said the Home Office was the toughest job in government. It hasn't got easier. We should get a few facts straight. Crime has fallen not risen. We are the only government since the war to do it (Blair, 2006). 
The image of 'toughness' is applied both to the politics of crime and to the policies implemented to fight it. The occurrence of straight in the second part of the quote is coherent with the Strict Father frame, as it points to one of its constitutive metaphors as identified by Lakoff (2002) and confirmed by Cienki (2005a): BEING MORAL IS BEING UPRIGHT.

Blair's and Labour's 'tough' rhetoric is also constructed through a consistent use of multimodal resources, sometimes independently from the text of the speech. We argue that Blair's positioning (Harré \& Langenhove, 1999) as a strict father is visually enhanced by the recurrent use of the index finger pointed upwards. Throughout the speech, this gesture is performed in various forms, as illustrated in Figure 1: with the left hand or right hand and with one hand or two for extra emphasis (Müller, 2004).
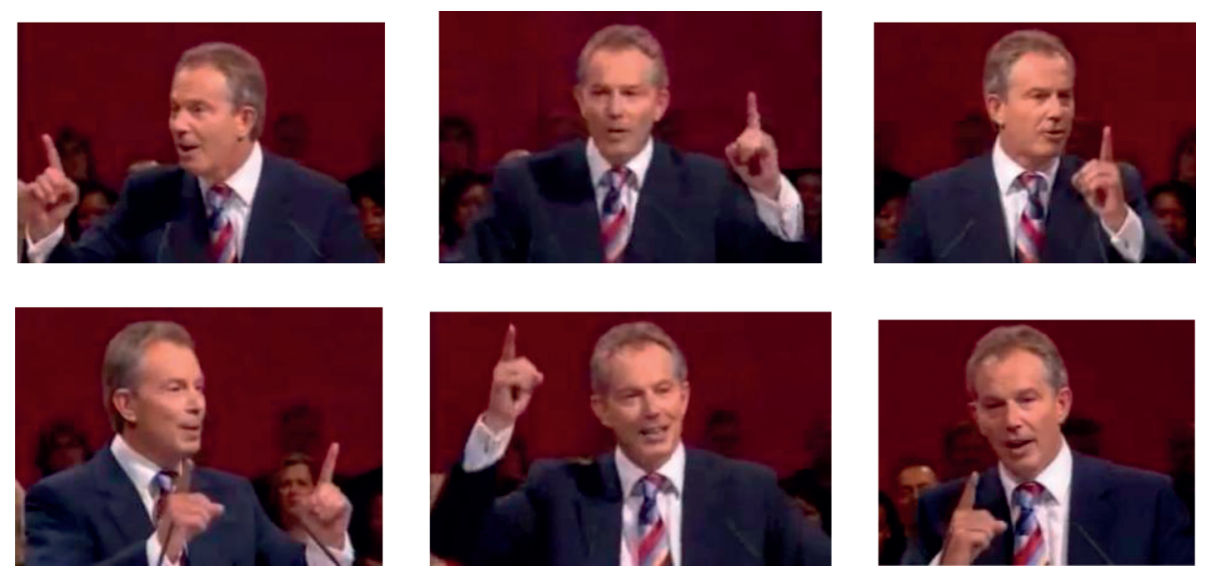

Figure 1. Blair's recurrent upward-pointed index gesture

This gesture form is combined with a large variety of verbal content, and is always synchronized with prosodic stress, as in examples (9) to (13).

(9) We have (...) not enough women MPs, but twice what there were (Blair 2006). ${ }^{16}$

(10) Manchester (...), a city that shows what a confident, open, and proud people with a great Labour council can do (Blair 2006).

(11) Last year China and India produced more graduates... graduates than all of Europe put together (Blair 2006).

(12) David Cameron's Tories? My advice: get after them (Blair 2006).

16. In this section's examples, boldface type is used to highlight prosodic stresses. 
(13) And I say to business: you have a responsibility to train your workforce (Blair 2006).

As a gesture form, the basic motivation of the upward-pointing index is deictic. ${ }^{17}$ And yet, in none of the aforementioned examples does Blair point at any object (concrete or abstract) ${ }^{18}$ or space located above himself, as evidenced by the type of verbal content this gesture combines with (twice, with, graduates, my advice, I say). Instead, this upward-pointing gesture is used as part of multimodal prosody (Bolinger, 1983; Ferré, 2012): the speaker synchronizes beat movements of the hand (McNeill, 2005) with vocal prosodic stresses to highlight - without actually pointing at - the importance of a specific element in the discourse and to bring it to the audience's attention. Thus in examples (9) to (13), as in the rest of the speech, the upward-pointing index takes on a pragmatic function (Streeck, 1994; 2009) rather than a referential one. The upward direction of the gesture does not take on its basic, spatial meaning but an abstract one (Cienki \& Müller, 2008). It can therefore be interpreted as the source domain for a metaphor, which can be formalized as X IS BEING PHYSICALLY UPRIGHT. Because gestures are schematic and underdetermined by nature (Cienki, 2005b; Lapaire, 2011), and because the meaning of a pragmatic gesture cannot be derived from the accompanying verbal content, the target domain of this metaphor cannot be identified with absolute certainty. Nonetheless, the potential target domains of this visual metaphor (including EMPHASIS, CORRECTNESS, DOMINANCE, or MORALITY) have a common denominator: they present the speaker as a figure of authority. This meaning is reminiscent of the culturally conventionalized use of this gesture as an emblem (Ekman \& Friesen, 1969) to scold or threaten children. The upward-pointing index creates an asymmetrical relation between speaker and audience, positioning the former as a source of power and normativity: the metaphor expressed in this case is likely to be BEING MORAL IS BEING UPRIGHT. According to this analysis, the upward-pointing index functions as a visual entailment of the Strict Father model (Cienki, 2005a), and Blair's recurrent use of this gesture contributes to positioning him as the authoritative source of the party's values. This casts a new light on examples (12) and (13), in which Blair gives marching orders, either to his supporters (get after them) or to a potentially dissenting entity (train your workforce).

17. See Kita (2008) for a detailed discussion of the rich variety of meanings of pointing gestures.

18. For a discussion of abstract deixis, see McNeill et al. (1993). 


\subsection{Talking progress}

Referential gestures (28 occurrences) are rarely used in Blair's speech, compared with pragmatic ones (296 occurrences). When Blair uses gestures affiliated with the propositional content of the speech (Butterworth, 1975), their function is usually an abstract referential (or metaphoric) one, relying on a basic orientational metaphor, which we connect with the party's established narrative of change and progress. For example, at 12'48, Blair recalls major steps in the history of the Labour party, and more specifically the divided reception of Harold Wilson's audacious proposals in the 1960s. He explains:

(14) Everyone was telling Harold Wilson not to push it. They said it was divisive, unnecessary (Blair 2006).

In (14), the three words Wilson, push and divisive receive extra prosodic salience, with vocal stresses synchronized with three gestural beats. The shape of the hand indicates a link with the metaphor push it, which is also at the centre of the prosodic salience. Both palms are flat, facing Blair's body and form an imaginary vertical plane (see Figure 2). On each prosodic beat, the hands move forward and down, as though marking steps in a progression.

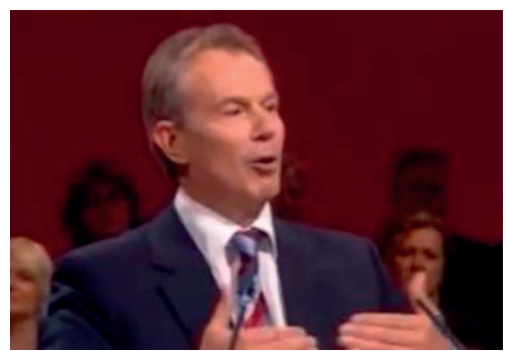

Figure 2. Both palms with extended fingers facing the torso move forward and down on "push it"

Even though people were discouraging Wilson from 'pushing' things in a certain direction, the spatial meaning of the lexeme push implies a movement forward that is reflected in the gesture. Blair suggests that innovation was in fact the right choice, and this idea is immediately stated in his next utterance:

(15) In the end he gave up, but so did the public on Labour (Blair, 2006).

In (15), Blair does not gesture at all and uses the lower pitch of his voice: his grave and distanced attitude reinforces his criticism of Wilson's choices. 
Gesture space and orientation are organized in a highly consistent way in this speech, since another version of this gesture, performed only with one hand this time, occurs a minute before (at 11'41), as illustrated in Figure 3.

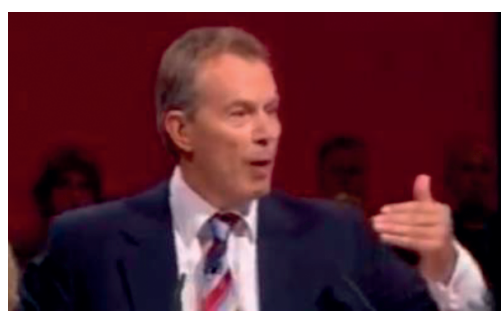

Figure 3. Extended fingers facing the torso move forward and down on "on the way up"

The orientational metaphor in this gesture (forward movement) is closely synchronized with another orientational metaphor in the text (GOOD IS UP), as the three strokes of this gesture highlight the word stresses in up, ambitious and themselves in (16):

(16) We reach out not just to those in poverty or need but those who are doing well but want to do better; those on the way up, ambitious for themselves and their families (Blair, 2006).

Throughout the speech, Labour's narrative of progress and change is asserted and emphasized by speech-gesture combinations of forward and upward movements. More specifically, in this last example, Blair skilfully blends two deep frames typical of new Labour discourse. Progress is associated with defending the British population as a whole: not just the underprivileged (those in poverty or need) but the well-off as well (ambitious for themselves and their families). New Labour's narrative of progress is thus conflated with Labour's shift from the party of the people, (i.e. representing the working class) to being the people's party (i.e. representing everyone).

\subsection{The people's party}

One last recurrent pragmatic gesture in Blair's speech is an extended arm with an open, slightly curved palm with extended fingers, but this time open to the side. This gesture can be performed with one hand only or with both hands. By its form, direction and function (Blair often uses it to introduce a new idea in speech) this pragmatic gesture is clearly an interactive one (Bavelas et al., 1995). In ordinary conversations, interactive gestures presenting a new idea in the speech are usually performed with a horizontal open palm facing upwards. So by opening his arm to the side with the result of an oblique or vertical palm facing the audience, Blair is 
at the same time presenting new ideas and including his audience in his speech. In variations of the gesture performed with one arm, Blair appears to simply reinforce the interpersonal dimension of his speech when highlighting a new idea. In other more emphatic versions of the gesture, particularly those performed with both arms, the effect is much more theatrical: Blair visually includes his audience, by embracing his party members with his whole body, as shown in Figure 4 .

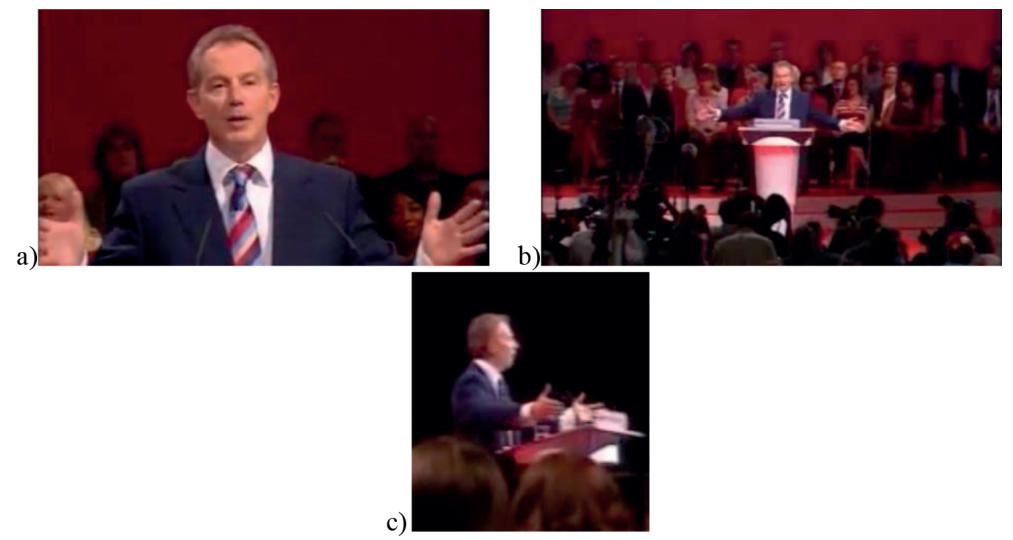

Figure 4. Extended arms with open palms facing away: Blair's gesture of inclusion

In picture $4 \mathrm{~b}$, the gesture is performed on the phrase for us as a party: Blair is simultaneously voicing and physically enacting the party's unity. Interestingly, the professionals who edited the video of the speech also noticed this multimodal strategy and chose to enhance it, by zooming out in an extreme long shot, dramatizing Blair's performance of this ample gesture. Part of Blair's illocutionary point is to take the audience under his wing: this dramatic gesture reinforces the bond between the leader and his party. It serves as a visual contribution to the discourse of inclusion that equates new Labour with 'the people's party', as in (17) and its associated gesture in Figure 5:

(17) Thank you to you, our party, our members, our supporters, the people who week in, week out do the work, take the flak but don't often get the credit (Blair 2006).

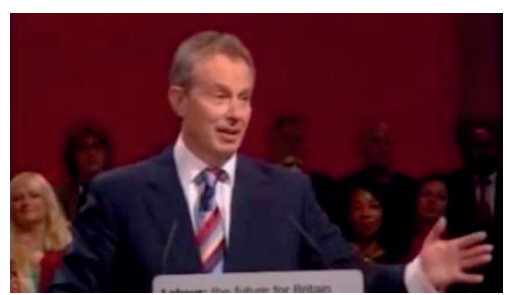

Figure 5. Vertical left palm facing the audience on "take the flak" 
Here, the apparent paradox of relying on a 'nurturant' gesture (Lakoff, 2002) while using a war-like metaphor in speech (take the flak) is quickly resolved, as the goal of the speaker is to perform an act of fairness and care towards members of the party who usually go unrecognised for their efforts. This recurrent gesture positions Blair as a protective leader, who guarantees the party's unity. It fleshes out the recurring themes of embrace, reconciliation, unity and inclusion that are typical of new Labour's self-defining discourse.

In order to reinforce new Labour's image as the unifying, consensual people's party, Blair makes repeated use of antanaclasis - the association of multiple meanings of the same word (or idea), some literal, some metaphorical. This strategy allows him to create smooth transitions from concrete achievements to issues concerning the Labour party's collective identity, as in (18), in which Blair proposes to define the aimed electorate of the Labour party:

(18) The core vote of this party today is not the heartlands, the inner city, not any sectional interest or lobby. Our core vote is $(.)^{19}$ the country (Blair 2006).

This short passage illustrates what we analyse as an antanaclasis network in Blair's speech. The noun core is identified as a realisation of the basic metaphor CENTRAL IS IMPORTANT. It activates the basic meaning of the noun heart in the compound heartland: its basic sense is connected to the metaphorical sense of core, and its metaphorical meaning points to the subsequent reference to the inner city. The terms echo each other, as metaphorical meanings alternate with non-metaphorical meanings. They build a consistent image that is also a known metaphor of the country and the nation, namely THE NATION IS A PERSON. In (18), Blair marks every prosodic stress with a beat of the hand during the first part: "the core vote ... or lobby", before densifying beats and vocal stresses on the final utterance "our core vote is (.) the country". The continuity in the network of images is marked visually by continuity in gesture, since Blair relies on the same gesture form throughout the passage: a movement downward of the right hand with curled fingers apart from the index and middle finger that are extended, as illustrated in Figure 6.

The increased frequency of prosodic stresses towards the end adds to the dramatic intensity of the passage. The head nod immediately following "our core vote is the country" visually echoes this final assertion, giving it extra assertiveness and marking the conclusion of a vocal paragraph. The audience immediately acknowledges this multimodal dramatization by enthusiastically responding with a 14-second round of applause. Once again, Blair's speech is met with success as he connects the people's collective identity (this party) and concrete experience (the heartlands, the inner city) with their emotions and values (core vote).

19. The sign (.) indicates a short pause in the speech. 


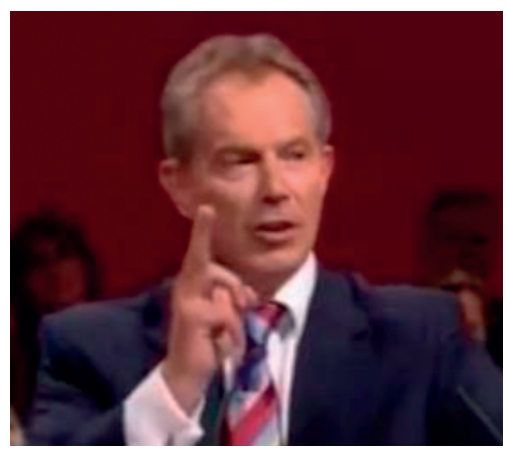

Figure 6. Marking prosodic stresses visually on "our core vote is the country"

\section{Conclusion}

In this paper, we have accounted for some of the major features that make political discourse effective, based on the example of political party conference speeches in contemporary Britain. We have taken up the "methodological synergy" propounded by Baker et al. (2008, p.274), by associating quantitative and qualitative analyses to propose a multimodal corpus-based analysis of political discourse. Our quantitative analyses have shown how the leader stages the speech as an informal exchange with his audience, and creates consensus over the party's values to ensure a privileged relationship with his supporters. The speech's politics are not about factual achievements, but rather about 'you' and 'I/me' standing for the same values. PCS stand out as a concentrate of the party's identity and values.

Zooming in on Blair's last party conference speech as party leader in 2006 has allowed us to see how the micro-level reflects the macro-level of discourse. Blair's positioning as a Strict-Yet-Inclusive Father plays out in the recurrent use of hand gestures that are compatible entailments of this diffuse, complex deep frame. New Labour's defining features are also expressed visually: the POLITICS IS A JOURNEY metaphor is reflected through orientational metaphors in both text and gesture. Finally, gestures highlight stylistic strategies like antanaclasis, by visually indicating continuity in a network of images, relying on emotion to secure the speaker's bond with his audience.

Our corpus-based multimodal analysis of political discourse has allowed us to identify consistent patterns characteristic of party conference speeches in terms of framing and metaphors, at several levels of analysis. In the next steps of this project, we hope to apply this method to account for the specific features of other political discourse corpora. 


\section{Acknowledgments}

The authors would like to thank Julien Perrez and Min Reuchamps for including us in this special issue, and for regularly bringing together researchers from various countries and disciplines to work together on political discourse, its creation and its reception. We would also like to thank the two anonymous reviewers, as well as Graham Low, for their very valuable comments and corrections on previous versions of this paper. All remaining inaccuracies are our own responsibility. Our use of Youtube screen shots from Tony Blair's 2006 party conference speech in Figures 1-6 follows accepted conventions of fair use.

\section{References}

Archer, D. (2009). Does frequency really matter? In D. Archer (Ed.), What's in a word-list? Investigating word frequency and keyword extraction (pp. 1-16). Farnham, UK: Ashgate.

Baker, P. (2004). Querying keywords: Questions of difference, frequency, and sense in keywords analysis. Journal of English Linguistics 32(4), 346-359.

Baker, P. (2006). Using corpora in discourse analysis. London: Continuum.

Baker, P., Gabrielatos, C., Khosravinik, M., Krzyżanowski, M., McEnery, T., \& Wodak, R. (2008). A useful methodological synergy? Combining critical discourse analysis and corpus linguistics to examine discourses of refugees and asylum seekers in the UK Press. Discourse \& Society, 19(3), 273-306. DOI: 10.1177/0957926508088962

Bale, T. (2010). The conservative party: From Thatcher to Cameron. Cambridge, UK: Polity Press.

Barlow, M. (2000). Usage, blends and grammar. In M. Barlow \& S. Kemmer (Eds.), Usage-based models of language (pp.315-345). Stanford, CA: CSLI Publications.

Bavelas, J., Chovil, N., Coates, L., \& Roe, L. (1995). Gestures specialized for dialogue. Personality and Social Psychology Bulletin, 21(4), 394-405. DOI: 10.1177/0146167295214010

Benveniste, E. (1966). Problèmes de linguistique générale. Bibliothèque Des Sciences Humaines. Paris: Gallimard.

Bolinger, D. (1983). Intonation and gesture. American Speech, 58(2), 156-174.

DOI: $10.2307 / 455326$

Bull, P. (2012). The microanalysis of political discourse. Philologia Hispalensis, 26, 79-93.

Butterworth, B. (1975). Hesitation and semantic planning in speech. Journal of Psycholinguistic Research, 4(1), 75-87. DOI: 10.1007/BF01066991

Cienki, A. (2005a). Metaphor in the 'strict father' and 'nurturant parent' cognitive models: Theoretical issues raised in an empirical study. Cognitive Linguistics, 16(2), 279-312. DOI: $10.1515 / \operatorname{cog} l .2005 .16 .2 .279$

Cienki, A. (2005b). Image schemas and gesture. In B. Hampe (Ed.), From perception to meaning: Image schemas in cognitive linguistics (pp.421-442). Berlin: Mouton de Gruyter. DOI: $10.1515 / 9783110197532.5 .421$

Cienki, A., \& Müller, C. (Eds.). (2008). Metaphor and gesture. Amsterdam: John Benjamins. DOI: $10.1075 /$ gs.3

Charteris-Black, J. (2004). Corpus approaches to critical metaphor analysis. Houndmills, UK: Palgrave Macmillan. DOI: 10.1057/9780230000612 
Ekman, P., \& Friesen, W. (1969). The repertoire of nonverbal behavior: Categories, origins, usage, and coding. Semiotica, 1(1), 49-98. DOI: 10.1515/semi.1969.1.1.49

Faucher-King, F. (2005). Changing parties : An anthropology of British political party conferences. Houndmills, UK: Palgrave Macmillan.

Ferré, G. (2012). Functions of three open-palm hand gestures. Multimodal Communication, $1(1), 5-20$.

Fillmore, C. (1982). Frame semantics. In The Linguistic Society of Korea (Ed.), Linguistics in the morning calm: Selected papers from SICOL-1981 (pp.111-137). Seoul, Korea: Hanshin Pub. Co.

Finlayson, A., \& Martin, J. (2008). 'It ain't what you say...': British political studies and the analysis of speech and rhetoric. British Politics, 3(4), 445-464. DOI: 10.1057/bp.2008.21

Harré, R., \& Langenhove, L. (1999). Positioning theory: Moral contexts of intentional action. Oxford: Blackwell.

Heritage, J., \& Greatbatch, D. (1986). Generating applause: A study of rhetoric and response at party political conferences. American Journal of Sociology, 92(1), 110-157.

DOI: $10.1086 / 228465$

Horton, D., \& Wohl, R. (1956). Mass communication and para-social interaction: Observations on intimacy at a distance. Psychiatry, 19, 215-229.

Kendon, A. (2004). Gesture: Visible action as utterance. Cambridge \& New York: Cambridge University Press. DOI: 10.1017/CBO9780511807572

Kita, S. (2008). Pointing: Where language, culture and cognition meet. Mahwah \& London: Lawrence Erlbaum.

Kövecses, Z. (2002). Metaphor: A practical introduction. Oxford: Oxford University Press.

L'Hôte, E. (2014). Identity, narrative and metaphor: A corpus-based cognitive analysis of new labour discourse (1994-2007). London: Palgrave Macmillan.

L'Hôte, E. (2010). New Labour and globalization: Globalist discourse with a twist? Discourse \& Society, 21(4), 355-376. DOI: 10.1177/0957926510366212

L'Hôte, E., \& Lemmens, M. (2009). Reframing treason: Metaphors of change and progress in new Labour discourse. CogniTextes, 3, http://cognitextes.revues.org/248.

Lakoff, G. (1993). The contemporary theory of metaphor. In A. Ortony (Ed.), Metaphor and thought (2nd Edition, pp. 202-251). Cambridge, UK: Cambridge University Press.

Lakoff, G. (2002). Moral politics: How liberals and conservatives think. Chicago, IL: University of Chicago Press. DOI: 10.7208/chicago/9780226471006.001.0001

Lakoff, G. (2006). Thinking points: Communicating our american values and vision. New York: Farrar, Straus and Giroux.

Lapaire, J.-R. (2011). Grammar, gesture and cognition: Insights from multimodal utterances and applications for gesture analysis. Вісник Львівського університету. Серія філологічна, 52, 87-107.

Mair, P. (1994). Party organizations: From civil society to the state. In R. S. Katz \& P. Mair (Eds.), How parties organize: Change and adaptation in party organizations in Western democracies (pp.113-35). London, Thousand Oaks: Sage.

Mariot, N. (2006). Le frisson fait-il la manifestation? Pouvoirs, 1, 97-109. DOI: $10.3917 /$ pouv.116.0097

Mariot, N. (2009). Le paradoxe acclamatif, ou pourquoi les institutions n'ont pas de première fois. In F. Buton \& N. Mariot (Eds.), Pratiques et méthodes de la socio-histoire (pp. 169-90). Paris: Presses universitaires de France. 
McNeill, D. (2005). Gesture and thought. Chicago, IL: University of Chicago Press. DOI: $10.7208 /$ chicago/9780226514642.001.0001

McNeill, D., Cassell, J., \& Levy, E. T. (1993). Abstract deixis. Semiotica, 95(1/2), 5-19. DOI: $10.1515 /$ semi.1993.95.1-2.5

Meyer, C. F. (2002). English corpus linguistics: An introduction. Cambridge, UK: Cambridge University Press. DOI: 10.1017/CBO9780511606311

Minkin, L. (1978). The Labour Party conference: A study in the politics of intra-party democracy. London: Allen Lane.

Müller, C. (1998). Redebegleitende Gesten: Kulturgeschichte, Theorie, Sprachvergleich. Berlin: Spitz.

Müller, C. (2004). Forms and uses of the palm up open hand: A case of a gesture family? In C. Müller \& R. Posner (Eds.), The semantics and pragmatics of everyday gestures, Proceedings of the Berlin conference, April 1998 (pp. 233-256). Berlin: Weidler Buchverlag.

Oakes, M. P. (1998). Statistics for corpus linguistics. Edinburgh: Edinburgh University Press.

Pettitt, R. T. (2012). Me, myself and I: 'Self-referencing' in Labour Party conference leaders' speeches. British Politics, 7(2), 111-34. DOI: 10.1057/bp.2012.2

Pragglejaz Group. (2007). MIP: A method for identifying metaphorically used words in discourse. Metaphor and Symbol, 22(1), 1-39. DOI: 10.1080/10926480709336752

Rayson, P. (2003). Matrix: A statistical method and software tool for linguistic analysis through corpus comparison. Unpublished Doctoral Thesis, Lancaster University, Lancaster.

Rayson, P. (2008). From key words to key semantic domains. International Journal of Corpus Linguistics, 13(4), 519-549. DOI: 10.1075/ijcl.13.4.06ray

Rayson, P. (2009). Wmatrix: A web-based corpus processing environment. Computing Department, Lancaster University. http://ucrel.lancs.ac.uk/wmatrix/

Sinclair, J. (1991). Corpus, concordance, collocation. Describing English Language. Oxford: Oxford University Press.

Steen, G., Dorst, A., Herrmann, B., \& Kaal, A. (2010). A method for linguistic metaphor identification: From MIP to MIPVU. Amsterdam: John Benjamins. DOI: 10.1075/celcr.14

Streeck, J. (2009). Gesturecraft: The manu-facture of meaning. Amsterdam: John Benjamins. DOI: $10.1075 /$ gs.2

Streeck, J. (1994). 'Speech-handling': The metaphorical representation of speech in gestures. A cross-cultural study. Austin (Texas): Unpublished manuscript.

\section{Authors' addresses}

Dr Camille Debras (Corresponding Author)

Université Paris Ouest Nanterre

UFR Langues et Cultures Étrangères

Bâtiment V, Casier 28

200 avenue de la République

92001 Nanterre Cedex, France

cdebras@u-paris10.fr
Dr Emilie L'Hôte

Université Paris 7 Denis Diderot

UFR d'Etudes Anglophones

Bâtiment Olympe de Gouges, Case 7046

5 rue Thomas Mann

75205 Paris Cedex 13, France

emilie.lhote@univ-paris-diderot.fr 


\section{Biographical note}

Camille Debras is a Lecturer (Maître de Conférences) in English Linguistics at the Université Paris Ouest Nanterre La Défense (France). Her research on the multimodality of spoken communication explores how speakers integrate speech, prosody and gesture to take stances and construct meaning intersubjectively.

Emilie L'Hôte is a Lecturer (Maître de Conférences) in English Linguistics at the Université Paris Diderot, Sorbonne Paris Cité (France). Her research interests include discourse analysis, cognitive linguistics and corpus linguistics; her main current project focuses on the analysis of new Labour discourse. 